\title{
The Influence of Varying Aluminium and Manganese Content on the Corrosion Resistance and Mechanical Properties of High Strength Steels
}

\author{
Jan Hajšman *, Ludmila Kučerová (1) and Karolína Burdová
}

check for updates

Citation: Hajšman, J.; Kučerová, L.; Burdová, K. The Influence of Varying Aluminium and Manganese Content on the Corrosion Resistance and Mechanical Properties of High Strength Steels. Metals 2021, 11, 1446. https://doi.org/10.3390/met11091446

Academic Editor: Dong-Woo Suh

Received: 12 August 2021

Accepted: 6 September 2021

Published: 13 September 2021

Publisher's Note: MDPI stays neutral with regard to jurisdictional claims in published maps and institutional affiliations.

Copyright: (c) 2021 by the authors. Licensee MDPI, Basel, Switzerland. This article is an open access article distributed under the terms and conditions of the Creative Commons Attribution (CC BY) license (https:// creativecommons.org/licenses/by/ $4.0 /)$.
Regional Technological Institute, University of West Bohemia, 30100 Pilsen, Czech Republic; skal@rti.zcu.cz (L.K.); kburdova@rti.zcu.cz (K.B.)

* Correspondence: janh@rti.zcu.cz; Tel.: +420-377638767

\begin{abstract}
The aim of this paper is to evaluate the influence of small variations in chemical composition on the corrosion resistance and mechanical properties of low-manganese and medium manganese high strength steels. Six different steels with manganese content varying from 1.5 to $4.0 \mathrm{wt} . \%$ and aluminium from 0.008 to $6.5 \mathrm{wt}$.\% were subjected to the analysis. The other subjects for evaluation included the effect of aluminium as a replacement for silicon, niobium microalloying and the effect of heat treatment. The effect of non-metallic inclusions on localized corrosion initiation and propagation was also documented. Using potentiodynamic testing, exposure testing, tensile and impact testing, it was found that the improvement in corrosion resistance associated with increasing aluminium content is accompanied by a significant deterioration of the mechanical properties. Niobium microalloying and heat treatment was found to have no quantifiable impact on the anti-corrosion properties. The effect of aluminium content proved to be superior to the effect of nonmetallic inclusions in terms of determining the overall corrosion resistance of the experimental steels.
\end{abstract}

Keywords: potentiodynamic testing; medium manganese high strength steel; TRIP steel; localized corrosion; niobium microalloying

\section{Introduction}

Over the last two decades there has been a trend towards replacing conventional mild steels with high strength steels (HSS) and advanced high strength steels (AHSS). Today, a newly produced car body contains on average $30 \%$ of HSS and AHSS materials. The main object focus of HSS/ AHSS research and development is on achieving an optimum strength-weight ratio. So far many researchers have concentrated on the effect of alloying elements on the mechanical properties which are essential in terms of the processability and safety of the final product [1,2]. Manganese, one of the main alloying elements in AHSS, ensures the stabilization of retained austenite and thus enables the use of the TRIP/TWIP effect during cold plastic deformation. Earlier grades of AHSS with manganese content around $20 \mathrm{wt} . \%$ exhibited elongation over $50 \%$ and strength up to $1000 \mathrm{MPa}$. Nevertheless, the current trend in AHSS development is to avoid any uneconomical alloying concepts, i.e., keeping the manganese content below $10 \mathrm{wt}$ \% while maintaining the exceptional mechanical properties of the steel $[3,4]$.

The addition of silicon as a substitutional element in AHSS ensures solid solution strengthening and suppresses the formation of carbides during heat treatment. Therefore the retained austenite becomes enriched in carbon, which increases its mechanical and thermal stability [5].

In recent years, there has been a trend towards using aluminium as either a partial or a total replacement for silicon. Aluminium has similar benefits to silicon, moreover it prevents silicon oxide formation on the steel surface, which can be detrimental to any possible 
subsequent surface treatments (e.g., hot-dip galvanizing). Another benefit of aluminium alloying is weight reduction. An increase in aluminium by $1 \mathrm{wt} . \%$ is linked to approximately $1.5 \%$ weight reduction of the steel. Nevertheless, a fully ferritic microstructure can form as a result of higher aluminium content $[3,4]$.

Niobium microalloying ( $0.01 \mathrm{wt} . \%)$ acts beneficially towards solid solution strengthening without any significant loss of ductility and toughness. It can also cause the formation of fine nitrides or carbonitrides, resulting in grain refinement [6,7]. Further, niobium was proved to suppress the undesirable formation of pearlite at slow cooling rates and thus facilitates the heat treatment process $[3,8]$.

Most research into corrosion properties of high strength steels has been focused mainly on stainless steels. Much less attention has been paid to the corrosion resistance of HSS and AHSS used in the automotive industry. Automotive HSS and AHSS are usually used as surface-treated (hot-dip galvanization). Nevertheless, their corrosion resistance still represents an important factor, which can have, among other things, a significant impact on the quality of the protective surface treatments [3,9].

The manganese contribution to anti-corrosion properties is rather detrimental, since it tends to dissolve into $\mathrm{Mn}^{2+}$ ions or form unstable oxides in acidic and neutral electrolytes. In alkaline aqueous solutions manganese precipitates to $\mathrm{Mn}(\mathrm{OH})_{2}$, which is only slightly soluble in $\mathrm{pH}>13$ into $\mathrm{HMn}^{2-}$ ions. However, aluminium and silicon do not passivate in strong alkaline solutions, making the manganese effect negligible $[10,11]$. In mildly acidic, neutral and mildly alkaline aqueous solutions, the aluminium improves the passivation ability of the steel by forming an $\mathrm{Al}_{2} \mathrm{O}_{3}$ protective layer. Zhang and $\mathrm{Zhu}$ [12] reported that $5 \%$ aluminium content can compensate for the detrimental effect of manganese in Fe-25Mn5Al-0.15C steel in a neutral aqueous solution. Moreover, the presence of both aluminium and manganese in the form of inclusions represents an important factor affecting the overall corrosion resistance of steels [13,14].

Multiple cases of niobium improving corrosion properties have been reported. Nguyen and Jung [15] found that niobium microalloying (0.05 to $0.1 \mathrm{wt} . \%)$ of a low alloy steel can significantly decrease the passive current density in strong acidic solution due to the formation of stable $\mathrm{NbO}_{2}$ and $\mathrm{Nb}_{2} \mathrm{O}_{5}$ oxides. Reportedly, niobium also helps to accelerate the formation of a compact layer of corrosion products $(\mathrm{FeO} \cdot \mathrm{OH})$, which decreases the corrosion rate. El-Taib Heakal et al. [16] reported that niobium microalloying (0.059 wt.\%) of low-manganese TRIP steel increased the passivation ability of other alloying elements $(\mathrm{Al}, \mathrm{Cr}, \mathrm{Ni}, \mathrm{Cu})$. Qiao et al. [17] documented the improvements of stress corrosion cracking resistance due to nanosized $\mathrm{NbC}$ precipitates in high strength low alloy steel in simulated sea water. The authors claim that the precipitates act as hydrogen traps to restrain the movement of hydrogen atoms inside the steel, thereby reducing the hydrogen diffusion coefficient and inhibiting the hydrogen-activated corrosion in hydrogen-rich conditions. The desired grain refinement effect of niobium can however be harmful to corrosion resistance. With the increasing area of grain boundaries, their energies and ionization tendencies increase as well, resulting in localized corrosion acceleration and propagation along the boundaries [18].

Heat treatment consisting of soaking in the austenite or ferrite-austenite region followed by tempering at bainite-formation temperature is a simple way to obtain a multiphase microstructure with well-balanced strength and ductility and it is frequently used in high strength TRIP steel processing. Kadowaki et al. revealed that the heat treatment in the intercritical temperature range can impede the segregation of ferrite forming elements at the grain boundaries and thus increases the resistance to localized corrosion [19].

The subject of the present study was to determine the way in which the alloying, employed primarily to improve the mechanical properties, affects the corrosion resistance of various advanced high strength steels. 


\section{Materials and Methods}

A set of six experimental steels was put together to evaluate the effect of various alloying elements. The chemical compositions of the steels, given in Table 1, originate from previous studies [3,20]. Analysis of the chemical composition was carried out using a Q4 TASMAN optical emission spectrometer (Bruker, Billerica, MA, USA) on the final rods. The final results represents the average value of three measurement repeats. The experimental materials can be divided into three groups (Table 1): Al-Mn type with manganese content varying from 1.5 to $3 \mathrm{wt} . \%$ and aluminium from 1.5 to $2 \mathrm{wt} . \%$; high alloyed $6 \mathrm{Al}-4 \mathrm{Mn}$ steel and Mn-Si type steels with very low aluminium, which differ only in niobium content.

Table 1. Chemical composition of experimental steels in wt.\%.

\begin{tabular}{|c|c|c|c|c|c|c|c|c|c|c|c|}
\hline Group & Material & $\mathrm{C}$ & $\mathrm{Si}$ & Mn & $\mathbf{P}$ & $\mathrm{Cr}$ & Al & $\mathrm{Nb}$ & $\mathrm{Ti}$ & $\mathbf{N}$ & Mn/A1 \\
\hline \multirow{3}{*}{ Al-Mn } & $1.5 \mathrm{Al}-1.5 \mathrm{Mn}$ & 0.2 & 0.6 & 1.5 & 0.008 & 0.19 & 1.5 & 0.06 & 0.0009 & 0.02 & 1 \\
\hline & 1.5Al-3Mn & 0.2 & 0.6 & 3.0 & 0.008 & 0.19 & 1.5 & 0.06 & 0.004 & 0.02 & 2 \\
\hline & $2 \mathrm{Al}-3 \mathrm{Mn}$ & 0.2 & 0.6 & 3.0 & 0.008 & 0.17 & 2.0 & 0.06 & 0.0002 & 0.01 & 1.5 \\
\hline $\begin{array}{l}6 \mathrm{Al}- \\
4 \mathrm{Mn}\end{array}$ & $6 \mathrm{Al}-4 \mathrm{Mn}$ & 0.2 & 0.6 & 4.0 & 0.008 & 0.14 & 6.5 & 0.06 & 0.002 & 0.02 & 0.6 \\
\hline \multirow{2}{*}{$\mathrm{Mn}-\mathrm{Si}$} & $\mathrm{Mn}-\mathrm{Si}$ & 0.2 & 1.8 & 1.5 & 0.008 & 0.008 & 0.008 & 0.03 & 0.0002 & 0.004 & - \\
\hline & $\mathrm{Mn}-\mathrm{Si}-\mathrm{Nb}$ & 0.2 & 1.8 & 1.5 & 0.008 & 0.008 & 0.008 & 0.06 & 0.0002 & 0.007 & - \\
\hline
\end{tabular}

The materials were present in as-received state (forged into $20 \mathrm{~mm}$ diameter bars, air cooled and annealed) and as additionally heat treated (marked "HT"). $50 \mathrm{~kg}$ ingots with $125 \mathrm{~mm}$ top diameter, $110 \mathrm{~mm}$ bottom diameter and $500 \mathrm{~mm}$ height were vacuum cast. Before the forging the ingots were cut to remove the schrinkage cavity. Then the material was cut into four equal parts. Open die forging was performed using a CKW 6000 hydraulic press (ŽĎAS a.s., Žd'ár nad Sázavou, Czech Republic). The cross section of the workpiece was reduced to 35 by $35 \mathrm{~mm}$ using flat dies, subsequently concave dies were used for the final reduction to $20 \mathrm{~mm}$ diameter bars. The forging reduction was the same for all samples. The forging and annealing conditions (Table 2) were designed in previous experiments $[3,20]$ to provide optimum mechanical properties or a suitable initial microstructure for subsequent heat treatment.

Table 2. Experimental steels—forging and annealing parameters.

\begin{tabular}{|c|c|c|c|}
\hline Group & Material & Forging Temperature & $\begin{array}{l}\text { Annealing } \\
\text { Conditions }\end{array}$ \\
\hline \multirow{2}{*}{ Al-Mn } & $1.5 \mathrm{Al}-1.5 \mathrm{Mn}$ & $\begin{array}{l}1050{ }^{\circ} \mathrm{C} / 60 \text { min dwell, } \\
\text { air cooled to RT }\end{array}$ & Furnace-cooled only \\
\hline & $\begin{array}{l}1.5 \mathrm{Al}-3 \mathrm{Mn} \\
2 \mathrm{Al}-3 \mathrm{Mn}\end{array}$ & $\begin{array}{l}- \\
-\end{array}$ & $\begin{array}{c}950^{\circ} \mathrm{C} / 2 \mathrm{~h} \text { (argon) } \\
1000^{\circ} \mathrm{C} / 2 \mathrm{~h} \text { (argon) }\end{array}$ \\
\hline 6Al-4Mn & $6 \mathrm{Al}-4 \mathrm{Mn}$ & $\begin{array}{l}1050{ }^{\circ} \mathrm{C} / 60 \text { min dwell, } \\
\text { air cooled to RT }\end{array}$ & Furnace-cooled only \\
\hline $\mathrm{Mn}-\mathrm{Si}$ & $\begin{array}{c}\mathrm{Mn}-\mathrm{Si} \\
\mathrm{Mn}-\mathrm{Si}-\mathrm{Nb}\end{array}$ & $\begin{array}{l}1150{ }^{\circ} \mathrm{C} / 60 \text { min dwell } \\
\text { air cooled to RT }\end{array}$ & $\begin{array}{c}950{ }^{\circ} \mathrm{C} / 2 \mathrm{~h} \text { (argon) } \\
-\end{array}$ \\
\hline
\end{tabular}

The additional heat treatment procedure consisted of austenitization above Ac3 temperature at $950{ }^{\circ} \mathrm{C}$ for $30 \mathrm{~min}$, oil-cooling to $420^{\circ} \mathrm{C}, 30 \mathrm{~min}$ dwell at $425^{\circ} \mathrm{C}$ and air cooling. This procedure is intended to provide an optimum bainitic-martensitic microstructure, with retained austenite content up to approximately $15 \%$ [3,21-25].

Metallographic cross-sections in the longitudinal direction of the bar were prepared and inclusions and microstructure were analysed using a BX61 light microscope (Olympus, Shinjuku, Tokyo, Japan). The inclusion area was measured on five samples of each material at magnification $100 \times$. Retained austenite content was analysed using an X'Pert PRO 
RTG diffractometer with an $X^{\prime}$ celerator detector (Malvern Panalytical, Malvern, UK). The measurement was performed using Co $\mathrm{K} \alpha$ radiation (lambda $=0.1789 \mathrm{~nm}$ ). Phase identification was performed with X'Pert HighScore Plus software (4.1, Malvern, UK) using PDF4 database. Rietveld refinements were performed by MAUD V-2.94 free software (2.94, Trento, Italy). For each sample, following austenite peaks were analysed: (111), (002), (022), (113), (222). The analysed ferrite peaks included: (011), (002), (112) and (022). Potentiodynamic corrosion tests were performed at room temperature on samples ground with 500 grit $\mathrm{SiC}$ paper. The roughness parameters of the sample surface were measured using an Olympus LEXT OLS 3D measuring microscope (Olympus, Shinjuku, Tokyo, Japan). For each steel, five linear measurements were performed with analysed length of $2.5 \mathrm{~mm}$. The average values for all samples are following (including standard deviation) $\mathrm{Ra}=6.9 \pm 0.3 \mu \mathrm{m} ; \mathrm{Rpk}=10.6 \pm 0.9 \mu \mathrm{m} ; \mathrm{Rk}=20 \pm 1 \mu \mathrm{m}$. The electrochemical cell used $\mathrm{a}$ saturated calomel reference electrode and platinum wire as the auxiliary electrode. $8 \mathrm{~mL}$ of $3.5 \mathrm{wt}$ \% $\mathrm{NaCl}$ solution was used as electrolyte. The area exposed to the electrolyte was $0.2374 \mathrm{~cm}^{2}$. First, the system was left to rest for $30 \mathrm{~min}$ and then the test was carried out over a potential range from -0.1 to $1 \mathrm{~V}$. The potential and current was monitored by a SP-150-Bio Logic potentiostat (Biologic, Seyssinet-Pariset, France). The test was repeated three times for each material. An exposure test was conducted in a Q-FOG CCT (Q-Lab, Westlake, OH, USA) condensation chamber. Samples with $16 \mathrm{~mm}$ diameter and $5 \mathrm{~mm}$ thickness were ground with 500 grit $\mathrm{SiC}$ paper. The test cycle consisted of $8 \mathrm{~h}$ exposure at $40{ }^{\circ} \mathrm{C}$ and $100 \%$ humidity generated from demineralized water and $16 \mathrm{~h}$ exposure only maintaining the temperature at $23{ }^{\circ} \mathrm{C}$. Three samples of each material were exposed to two test cycles. The area of corrosion products on the sample surface was measured with an Olympus BX 61 light microscope (Olympus, Shinjuku, Tokyo, Japan) equipped with Stream Motion software (2.5, Shinjuku, Tokyo, Japan) for image analysis. Weight loss evaluation was performed in accordance with EN ISO 8407. The corrosion products were removed by immersion in a solution of $50 \mathrm{wt} . \%$. hydrochloric acid $(\rho 20=1.18 \mathrm{~g} / \mathrm{mL})$ with $3.5 \mathrm{~g} / \mathrm{L}$ hexamethylenetetramine as a corrosion inhibitor. To measure the weight losses an ENTRIS224i-1S analytical scale (Sartorius, Goettingen, Germany) with $0.1 \mathrm{mg}$ readability was used. To determine the mechanism of initiation and propagation of the corrosion process, micrographs of the initiation sites were taken. Metallographic cross sections were ground gradually with 80 to 2000 grit $\mathrm{SiC}$ paper, polished with $3 \mu \mathrm{m}$ and $1 \mu \mathrm{m}$ diamond paste, cleaned in ethanol and dried. Subsequently the samples were immersed in demineralised water. The immersion was interrupted at 1, 5, and 20 min intervals, samples were dried and light microscope images of the surface were taken. To induce a comparable corrosion process on $6 \mathrm{Al}-4 \mathrm{Mn}$ steel, it was necessary to employ a more aggressive electrolyte ( $3.5 \% \mathrm{NaCl}$ solution) and extend the immersion intervals to $20 \mathrm{~min}$, $1 \mathrm{~h}$ and $3 \mathrm{~h}$. The sites of localized corrosion after immersion were documented with a CrossBeam Auriga electron microscope (Zeiss, Oberkochen, Germany). EDS analysis of corrosion pits was then carried out. Mechanical properties were evaluated using tensile tests and Charpy impact tests of miniature samples (Figure 1).

Flat tensile samples (Figure 1a) and V-notched impact test samples (Figure 1b) were prepared with electrical discharge machining and additional grinding. An MTS servohydraulic testing device (MTS, Eden Prairie, MN, USA) was employed for tensile testing. The loading speed $0.01667 \mathrm{~mm} / \mathrm{s}$ was controlled using a Sobriety Monet 2D videoextensometer (Sobriety s.r.o., Kuřim, Czech Republic). An analogue Charpy test machine with an initial pendulum energy of $15 \mathrm{~J}$, was used to test the V-notched samples. No result correction was used for the mechanical testing, thus the results cannot be fully compared with standard full size tests. 


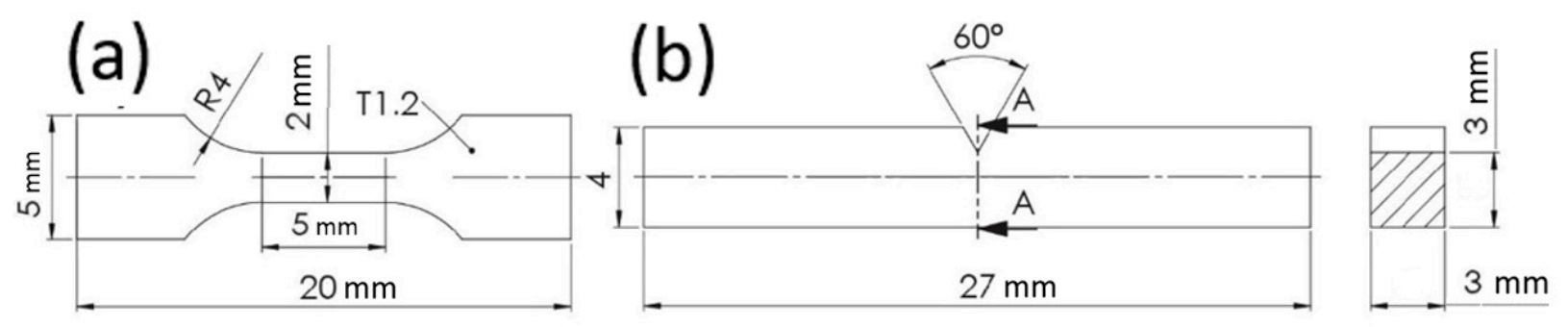

Figure 1. Samples for mechanical testing, (a) tensile test, (b) Charpy impact test.

\section{Results and Discussion}

\subsection{Microstructure}

Based on their microstructure, it is possible to divide the experimental steels into the same three groups as mentioned above. To demonstrate their characteristics, one representative steel was chosen from each group (Figure 2). The initial state Al-Mn group (Figure 2a) exhibited bainitic-martensitic microstructure with varying ferrite content which was the most significant in $1.5 \mathrm{Al}-1.5 \mathrm{Mn}$ steel (Figure 2a). The heat treatment refined the bainitic-martensitic component and removed the ferritic network (Figure 2b). Retained austenite content after heat treatment was $17 \%$ for $1.5 \mathrm{Al}-1.5 \mathrm{Mn}, 12 \%$ for $1.5 \mathrm{Al}-3 \mathrm{Mn}$ and $8 \%$ for $2 \mathrm{Al}-3 \mathrm{Mn}$. It is interesting to note the decrease of retained austenite content with increasing manganese content within the Al-Mn group. This phenomenon was previously registered by Grajcar et al. [26]. The authors suggest that due to the increased manganese content in medium manganese steels with $1.5 \mathrm{wt} . \%$ aluminium the carbon content in the $\gamma$ phase is reduced. Thus the $\gamma$ phase stability is decreased as well.

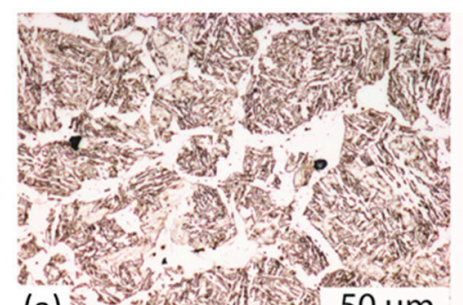

(a)

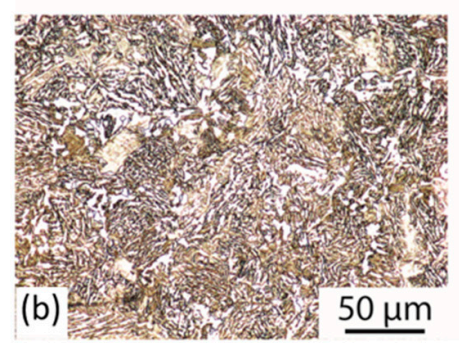

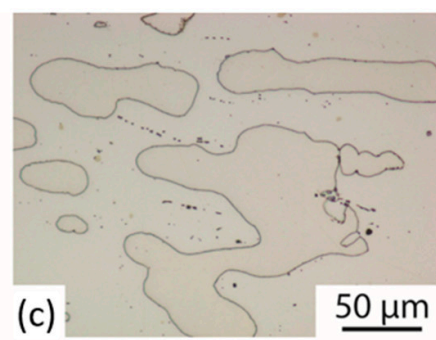

(c)

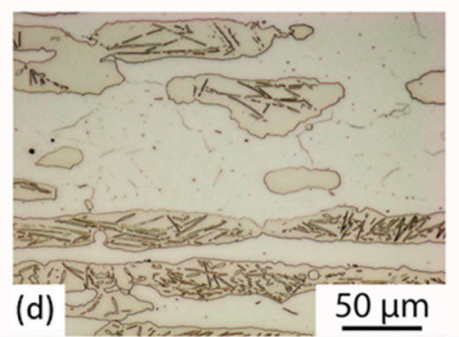

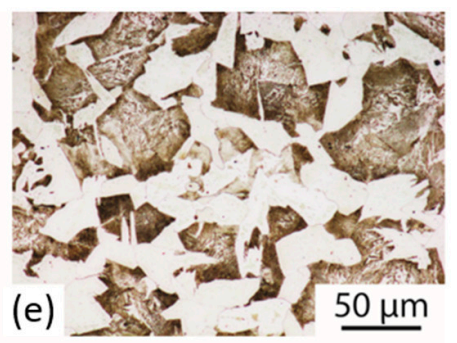

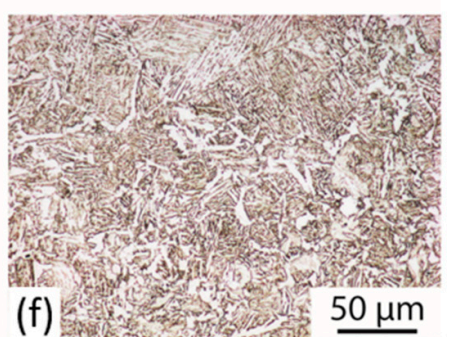

Figure 2. Development of microstructure; upper part—forged and annealed samples, lower partheat treated samples; (a,b) 1.5Al-1.5Mn steel; (c,d) 6Al-4Mn steel; (e,f) Mn-Si steel.

Figure $2 \mathrm{c}, \mathrm{d}$ prove that the increased content of alloying elements in steel $6 \mathrm{Al}-4 \mathrm{Mn}$ caused formation of a very distinctive microstructure consisting of ferrite, retained austenite and intermetallic compounds. The retained austenite content in the heat treated sample was determined to be $16 \%$. Despite the difficult interpretation of the RTG diffraction analysis of the intermetallic compounds in $6 \mathrm{Al}-4 \mathrm{Mn}$ steel, they can be identified as $\mathrm{FeAl}_{3}$, $\mathrm{FeAl}_{2}, \mathrm{C}_{0.14} \mathrm{Fe}_{1.86}$ and $\mathrm{C}_{0.12} \mathrm{Fe}_{1.88}$. Their content was not detectable due to low readability of the corresponding peaks. The heat treatment resulted in precipitation of longitudinal microstructural objects, previously identified as k-carbides ( $\mathrm{Fe}, \mathrm{Mn})_{3} \mathrm{AlC}$ [20]. The microstructure of the Mn-Si steel type initially consisted of coarse ferrite and pearlite. After 
the heat treatment both $\mathrm{Mn}-\mathrm{Si}$ and $\mathrm{Mn}-\mathrm{Si}-\mathrm{Nb}$ exhibited very similar bainitic microstructures with $12 \%$ retained austenite content for $\mathrm{Mn}-\mathrm{Si}$ and $9 \%$ for $\mathrm{Mn}-\mathrm{Si}-\mathrm{Nb}$.

The average distribution of inclusion size in the selected representative types is shown in Figure 3. The inclusions in 1.5Al-1.5Mn steel appear to be evenly distributed in the range from 10 to $120 \mu^{2}$, i.e., the Al-Mn type possesses the largest number of coarse inclusions. For both $6 \mathrm{Al}-4 \mathrm{Mn}$ and $\mathrm{Mn}-\mathrm{Si}$ steel more than $70 \%$ of the inclusions are smaller than $20 \mu^{2}$. Apparently, the increased aluminium content in 6Al-4Mn steel didn't cause any significant increase in inclusion content compared to the two other steel groups. This finding might be attributed to the vacuum casting process which reduces the aluminium oxide formation. However, the content of inclusions cannot be directly linked to aluminium since different types of inclusions (i.e., sulfidic) can be found in the present steels (Section 3.3).

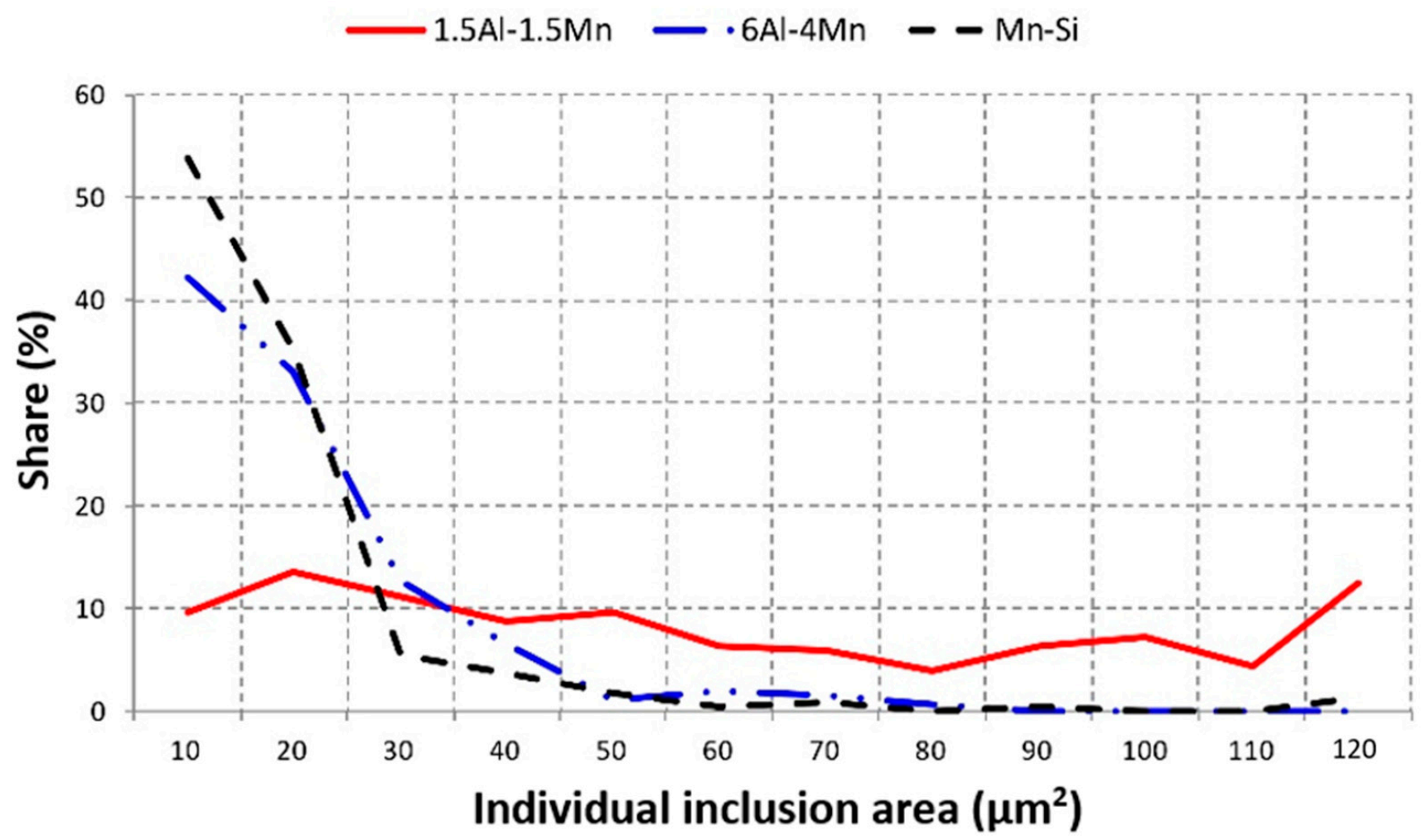

Figure 3. The distribution of the inclusion sizes in the steel samples.

\subsection{Corrosion Tests}

Based on the overall results of the polarization tests (Table 3), it can be concluded that the differences in corrosion potential, corrosion current density and corrosion rate, between particular materials are negligible. Corrosion potential value oscillated around $-700 \mathrm{mV}$ for all the experimental samples, however, the lowest average Ecorr was recorded for 6Al-4Mn steel $(-733 \mathrm{mV})$ and the highest for $1.5 \mathrm{Al}-1.5 \mathrm{Mn}(-680 \mathrm{mV})$. Nevertheless, in comparison to earlier high alloyed high strength steel grades with a similar $\mathrm{Al} / \mathrm{Mn}$ ratio, the results show a considerable improvement in the corrosion resistance of the materials [9,11,12,27-32]. For instance, Shih et al. [28] reported corrosion rates $580 \mu \mathrm{m} \cdot \mathrm{year}^{-1}$ and $570 \mu \mathrm{m} \cdot \mathrm{year}^{-1}$ for Fe-24.4Mn-9.96Al-0.40C and Fe-30.7Mn-13.03Al-0.44C alloys respectively, which were subjected to potentiodynamic testing in $3.5 \% \mathrm{NaCl}$ solution. Arguably, the improved corrosion resistance of the studied steels can also be attributed to relatively low manganese content (1.5 to $4 \mathrm{wt} . \%)$, which decreased the significance of the soluble corrosion products of manganese [10,12,33]. 
Table 3. Potentiodynamic test-average results of three repeats with standard deviation, F\&A—forged and annealed, HT-heat treated.

\begin{tabular}{|c|c|c|c|c|c|}
\hline Group & Material & Condition & Ecorr $(\mathrm{mV})$ & Jcorr $\left(\mathrm{mA} / \mathrm{cm}^{2}\right)$ & $\begin{array}{c}\text { Corrosion Rate } \\
\left(\mu \mathrm{m} \cdot \text { year }^{-1}\right)\end{array}$ \\
\hline \multirow{6}{*}{ Al-Mn } & \multirow{2}{*}{ 1.5Al-1.5Mn } & $\mathrm{F} \& \mathrm{~A}$ & $-680 \pm 22$ & $5 \pm 2$ & $6.8 \pm 0.7$ \\
\hline & & HT & $-694 \pm 14$ & $4.4 \pm 0.6$ & $4 \pm 2$ \\
\hline & \multirow{2}{*}{$1.5 \mathrm{Al}-3 \mathrm{Mn}$} & $F \& A$ & $-690 \pm 15$ & $7 \pm 2$ & $10 \pm 7$ \\
\hline & & $\mathrm{HT}$ & $-673 \pm 8$ & $4 \pm 2$ & $8 \pm 3$ \\
\hline & \multirow{2}{*}{ 2Al-3Mn } & $F \& A$ & $-701 \pm 16$ & $6 \pm 2$ & $6 \pm 2$ \\
\hline & & HT & $-718 \pm 9$ & $5 \pm 1$ & $5.0 \pm 0.9$ \\
\hline \multirow{2}{*}{$6 \mathrm{Al}-4 \mathrm{Mn}$} & \multirow{2}{*}{$6 \mathrm{Al}-4 \mathrm{Mn}$} & $\mathrm{F} \& \mathrm{~A}$ & $-733 \pm 17$ & $5 \pm 1$ & $6 \pm 2$ \\
\hline & & HT & $-715 \pm 37$ & $8 \pm 5$ & $7 \pm 4$ \\
\hline \multirow{4}{*}{$\mathrm{Mn}-\mathrm{Si}$} & \multirow{2}{*}{$\mathrm{Mn}-\mathrm{Si}$} & $F \& A$ & $-712 \pm 29$ & $3.2 \pm 0.1$ & $4 \pm 2$ \\
\hline & & HT & $-702 \pm 9.5$ & $6 \pm 2$ & $6 \pm 2$ \\
\hline & \multirow{2}{*}{$\mathrm{Mn}-\mathrm{Si}-\mathrm{Nb}$} & $\mathrm{F} \& \mathrm{~A}$ & $-685 \pm 22$ & $6 \pm 2$ & $12 \pm 7$ \\
\hline & & $\mathrm{HT}$ & $-712 \pm 25$ & $5 \pm 2$ & $5 \pm 1$ \\
\hline
\end{tabular}

Polarization curves of the selected steels (Figure 4) provide a more detailed insight into the corrosion behaviour of the three different material types. Although $6 \mathrm{Al}-4 \mathrm{Mn}$ steel shows the lowest average corrosion potential Ecorr, the anodic part of the corresponding polarization curve (dot-dashed line) exhibits the slowest increase of current density. The most rapid initial increase of anodic current density can be attributed to the Mn-Si steel type. The shape of the Al-Mn type curve is very similar to the Mn-Si type, however it typically shows slightly slower corrosion current density growth at the beginning of the anodic stage. These findings indicate the increased passivation tendency of the $6 \mathrm{Al}-4 \mathrm{Mn}$ sample. Neither the heat treatment nor the differences in chemical composition within the material groups were found to alter the shape of the anodic polarization curves in any significant way.
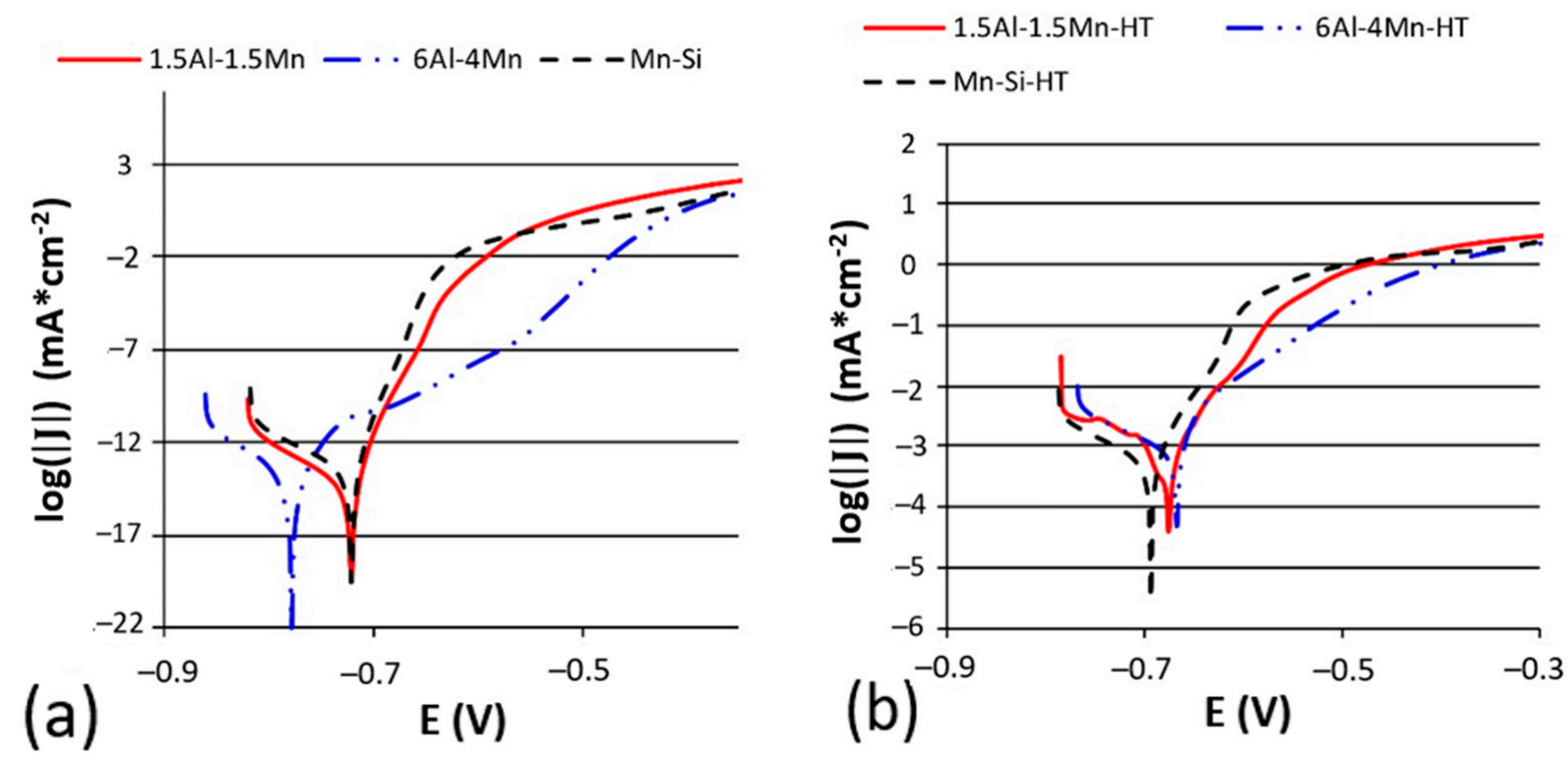

Figure 4. Polarization curves; (a) forged and annealed samples, (b) heat treated samples.

The quantity of corrosion products (Figure 5) and corresponding weight loss after exposure testing (Figure 6) follow the trend of the three distinct steel types. The 6Al-4Mn steel exhibits only mild pitting corrosion (Figure $5 b$ ) and the average weight losses for both forged and annealed and heat treated samples are below $1 \mathrm{mg}$. The most significant corrosion damage developed on the Mn-Si steels (Figure 5c). 

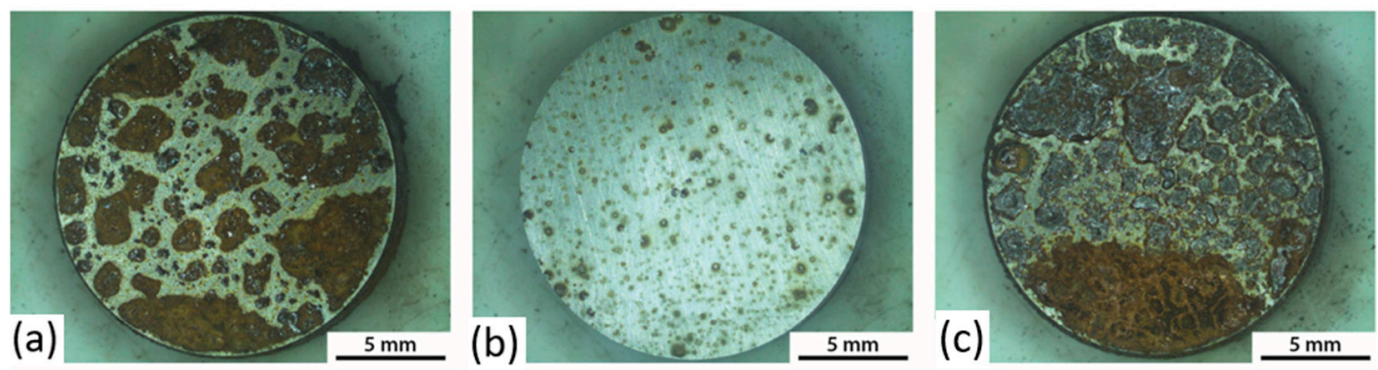

Figure 5. Representative samples after the condensation chamber exposure test; (a) Al-Mn type; (b) 6Al-4Mn steel; (c) Mn-Si type.

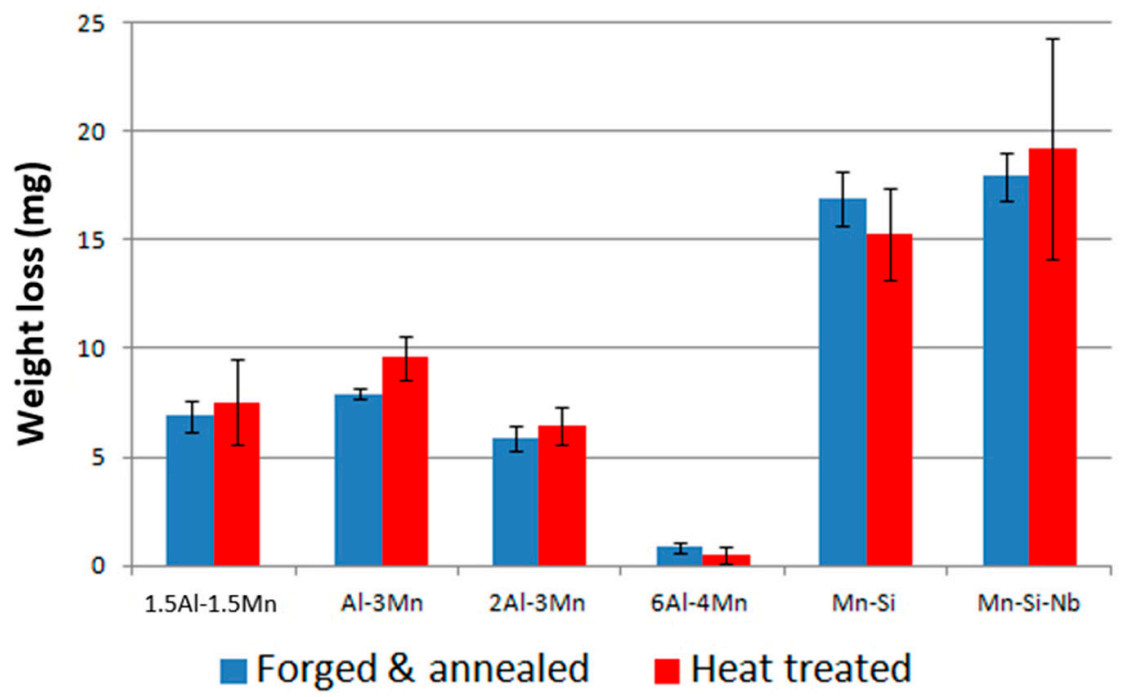

Figure 6. Exposure test-weight loss results.

This finding corresponds to the weight loss results (Figure 6) - the average weight loss of Mn-Si type ranged between $15 \mathrm{mg}$ and $19 \mathrm{mg}$. Medium corrosion damage was observed on the Al-Mn steel samples (Figure 5a), where the average weight loss ranges from $5 \mathrm{mg}$ to $10 \mathrm{mg}$.

\subsection{Corrosion Initiation Analysis}

In order to further investigate the differences in the corrosion behaviour of particular steels, the initiation of the corrosion process was studied via micrographs taken during the incremental immersion and subsequent EDS analysis of the initiation sites. Three representative examples are shown below (Figures 7-10).

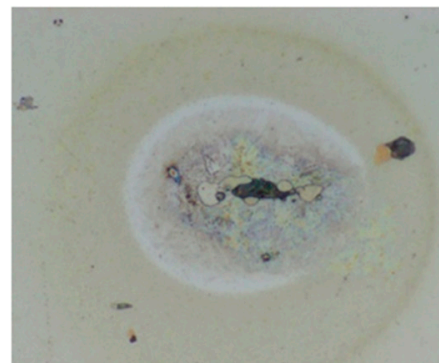

(a)

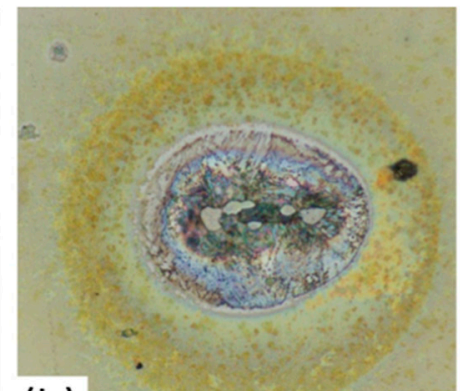

(b)
$20 \mu \mathrm{m}$

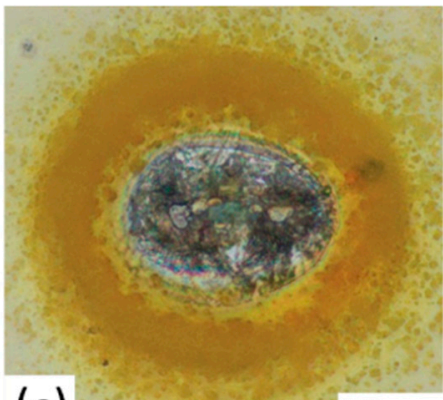

(c)

$20 \mu \mathrm{m}$

Figure 7. Corrosion pit, 1.5Al-3Mn-HT steel; (a) $1 \mathrm{~min}$, (b) $5 \mathrm{~min}$, (c) $20 \mathrm{~min}$ immersion (demineralized water). 

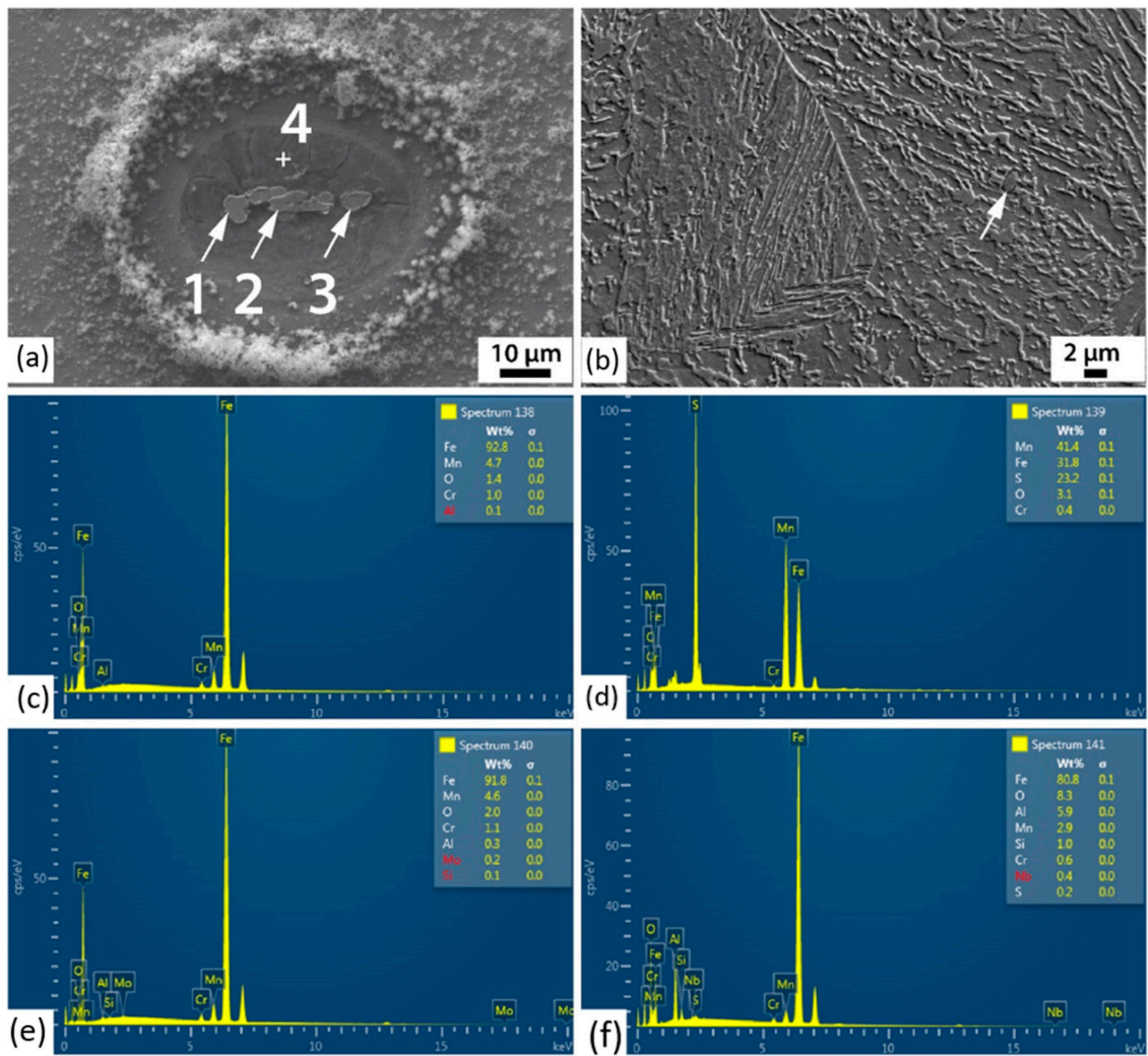

Figure 8. 1.5Al-3Mn-HT steel: (a) after 20 min immersion (demineralized water), corrosion pit with marked locations of EDS analysis; (b) polished and etched sample, arrow marking the M/A island; (c) EDS spectrum-point 1; (d) EDS spectrum-point 2; (e) EDS spectrum-point 3; (f) EDS spectrum-point 4.
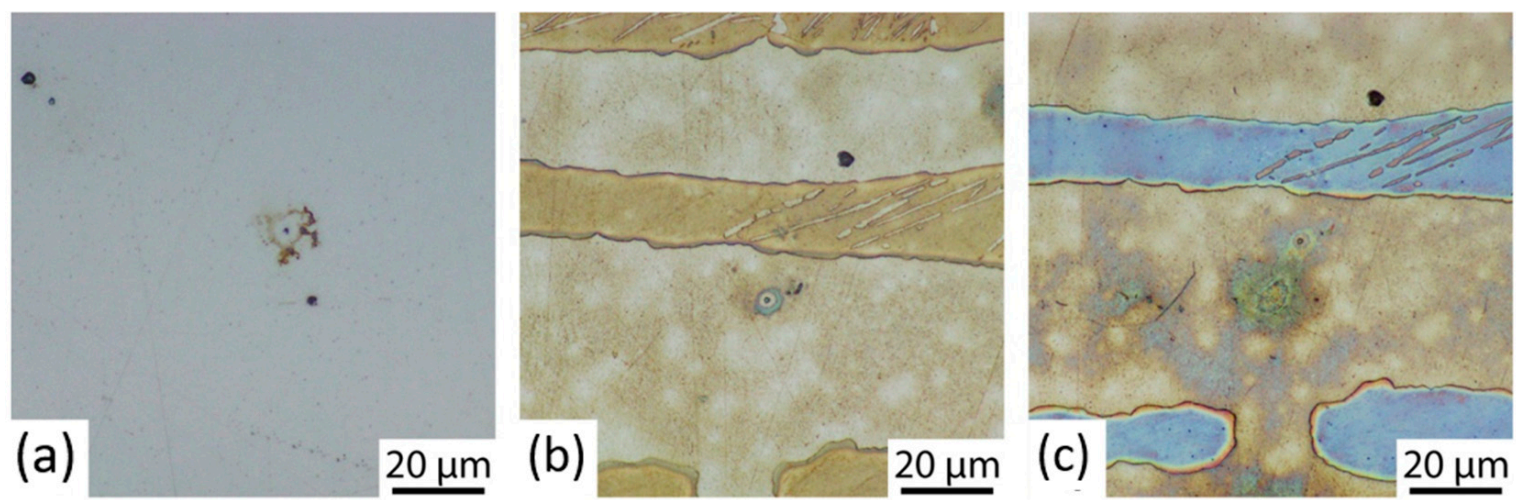

Figure 9. Corrosion pit, 6Al-4Mn-HT steel; (a) $5 \mathrm{~min}$ (b) 1 h, (c) $3 \mathrm{~h}$ immersion $(3.5 \% \mathrm{NaCl})$. 


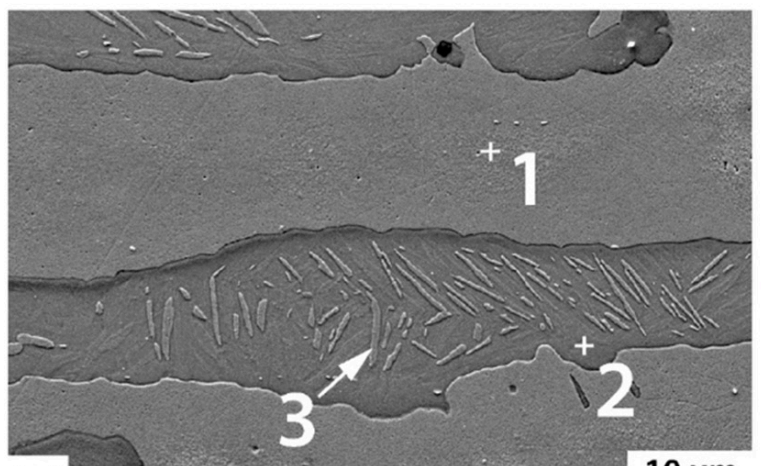

(a) $10 \mu \mathrm{m}$

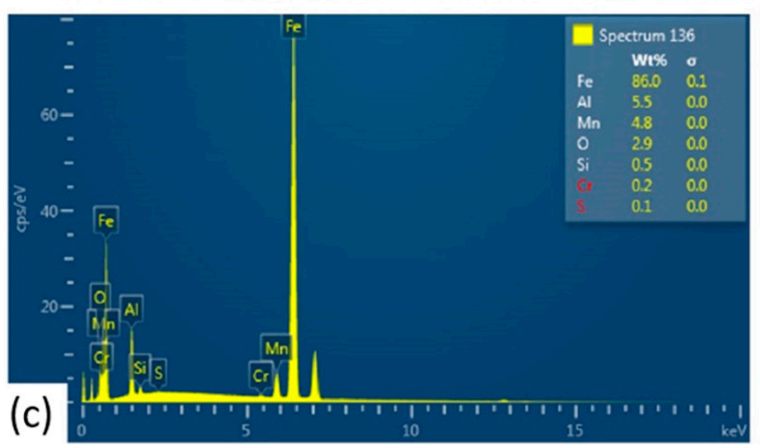

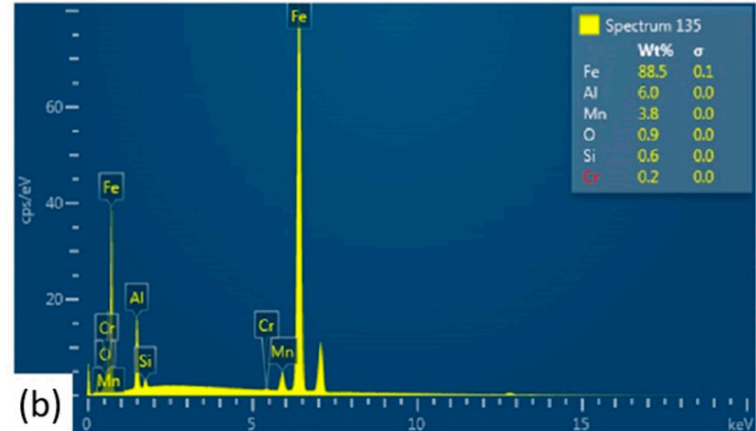

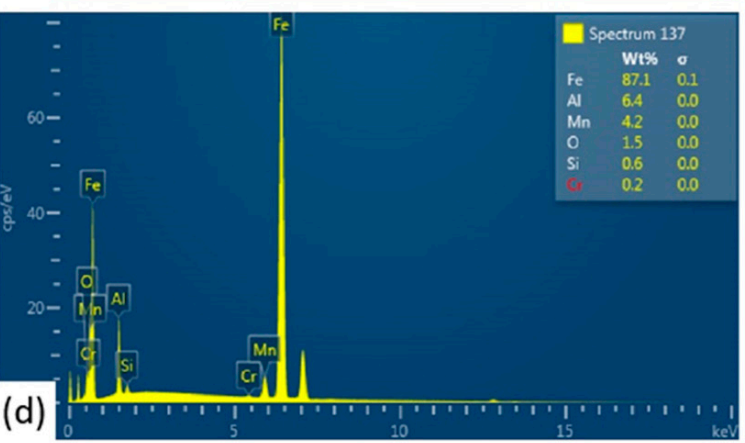

Figure 10. 6Al-4Mn after $3 \mathrm{~h}$ immersion (3.5\% NaCl), (a) marked locations of EDS analysis; (b) EDS spectrum-point 1; (c) EDS spectrum-point 2; (d) EDS spectrum-point 3.

Figure 7 shows the characteristic development of a corrosion spot in Al-Mn type steel. The corrosion process is initiated in the vicinity of coarse inclusion particles or more frequently inclusion clusters. It can be deduced that during the initial minute of immersion, the horizontal expansion of the corrosion pit is stopped and the material is further penetrated in the vertical direction. Based on the EDS analysis (Table 4) and comparison with earlier published studies [13,14,34-38], the inclusion particle in the centre of the corrosion pit can be identified as MnS (Figure 8a, point 2, Figure 8d). However the other particles inside the corrosion pit (Figure 8a, points 1,3) differ from the base material only by a slightly increased content of alloying elements (manganese, chromium) which, have apparently increased the corrosion potential of the particles in comparison to the surrounding bainitic microstructure. In a study published by Wei et al. [14] very similar particles in the microstructure of steel were attributed to M/A constituent islands, which formed microgalvanic couples with the bainitic phase and thus contributed to the acceleration of anodic dissolution of bainite due to corrosion potential differences. Although single M/A islands or M/A clusters were observed on polished and etched samples as well (Figure 8b), they were very difficult to detect through the microscopic observation. Nevertheless, these particles get highlighted by the corrosion process, since they were present along with the inclusions in all the corrosion pits formed on Al-Mn steel surface during the immersion.

Table 4. 1.5Al-3Mn-HT steel, results of EDS analysis of the corrosion spot in wt.\%.

\begin{tabular}{ccccccc}
\hline Point & O & Fe & Al & Mn & Cr & S \\
\hline 1 & 1.4 & 92.8 & - & 4.7 & 1.0 & - \\
2 & 3.1 & 31.8 & - & 41.4 & 0.4 & 23.2 \\
3 & 2.0 & 91.8 & - & 4.6 & 1.1 & - \\
4 & 8.3 & 80.8 & 5.9 & 2.9 & 0.6 & 0.2 \\
\hline
\end{tabular}


To induce any visible signs of the corrosion process on the 6Al-4Mn sample surface, a much longer immersion time in $3.5 \% \mathrm{NaCl}$ was necessary (Figure 9). Pitting corrosion initiation was observed only very rarely. The anodic dissolution appears to take place uniformly inside the islands of the minority phase (Figure $9 b, c)$.This phenomenon can be attributed to decreased aluminium and increased manganese content in the minority phase (Figure 2b,c, Table 5, points 1,2), which resulted in a lower passivation ability.

Table 5. 6Al-4Mn steel, results of EDS analysis after immersion in wt.\%.

\begin{tabular}{cccccc}
\hline Point & O & Fe & Al & Mn & Si \\
\hline 1 & 0.9 & 88.5 & 6.5 & 3.8 & 0.6 \\
2 & 2.9 & 86.0 & 5.5 & 4.8 & 0.5 \\
3 & 1.5 & 87.1 & 6.4 & 4.2 & 0.6 \\
\hline
\end{tabular}

Due to the smaller size of the inclusions, the Mn-Si steels (Figure 11) do not exhibit as significant vertical-oriented dissolution as the Al-Mn type. Also no M/A constituent islands were observed inside the corrosion spots in either Mn-Si steel. However, the dissolution takes place preferentially in the horizontal direction and apparently continues even after 5 min of immersion.

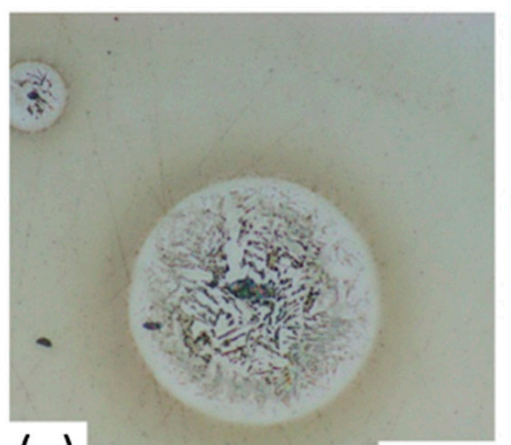

(a)

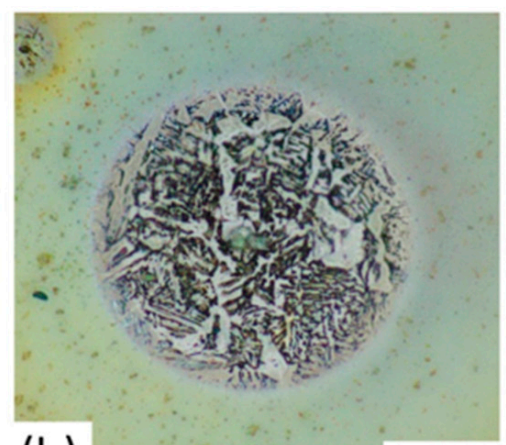

(b) $\underline{20 \mu \mathrm{m}}$

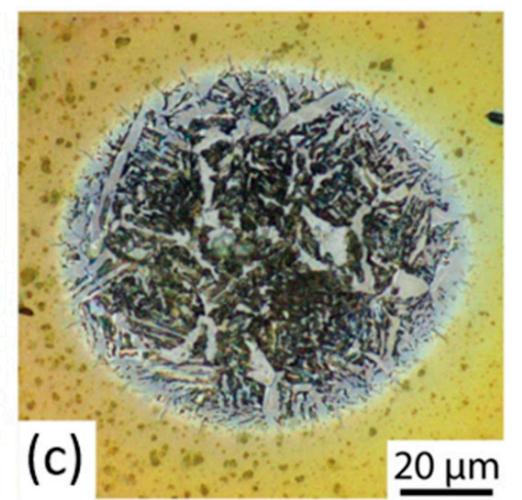

Figure 11. Corrosion pit, Mn-Si-HT steel: (a) $1 \mathrm{~min}$; (b) $5 \mathrm{~min}$; (c) $20 \mathrm{~min}$ immersion (demineralized water).

From the chemical composition of the inclusion (Figure 12, Table 6) and from literature $[13,14,35,37]$, it can be concluded that the corrosion pit in the Mn-Si steel was formed around a $\mathrm{MnS}+\mathrm{Al}_{2} \mathrm{O}_{3}$ complex inclusion.

Table 6. Mn-Si-HT steel, results from EDS analysis of the corrosion spot in wt.\%.

\begin{tabular}{ccccccc}
\hline Point & O & Fe & Al & Mn & S & Si \\
\hline 1 & 15.0 & 46.6 & 23.2 & 9.1 & 4.6 & 0.8 \\
2 & 0.7 & 95.3 & - & 1.8 & - & 1.4 \\
\hline
\end{tabular}

To quantify the effect of immersion on a particular steel, Figure 13 summarizes the corrosion spot diameters. The average spot diameters range from $15 \mu \mathrm{m}$ to $22 \mu \mathrm{m}$ for Al-Mn steels and from $63 \mu \mathrm{m}$ to $77 \mu \mathrm{m}$ for the Mn-Si type, i.e., the average corrosion spot diameter for the Mn-Si type is approximately three to five times larger than for the Al-Mn steel type. This phenomenon corresponds to a large extent with the weight loss results (Figure 6). In this case the results for $6 \mathrm{Al}-4 \mathrm{Mn}$ results are not included for the negligibility of size and number of the corrosion spots in the $6 \mathrm{Al}-4 \mathrm{Mn}$ sample. Again, the heat treatment was not found to have any distinct effect in terms of modifying the corrosion resistance. From the results depicted in Figures 3, 6 and 13, it can be concluded that in this case the larger inclusion size did not result in higher susceptibility to corrosion damage. When 
comparing the corrosion properties of Al-Mn and Mn-Si steel groups, any possible effect of chromium should be also considered.

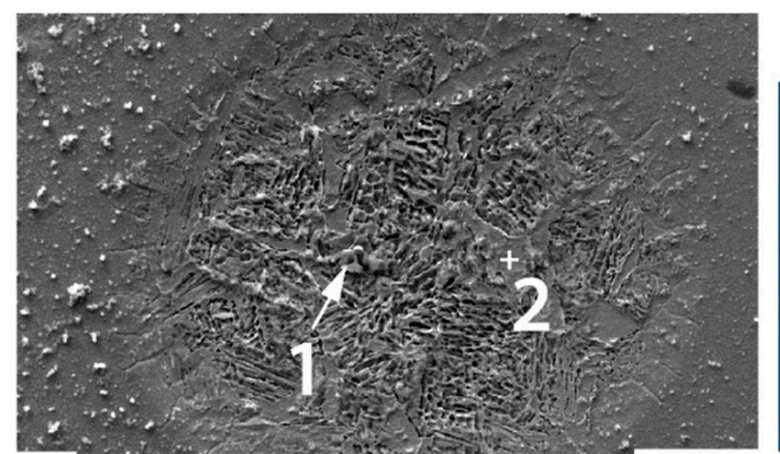

(a)

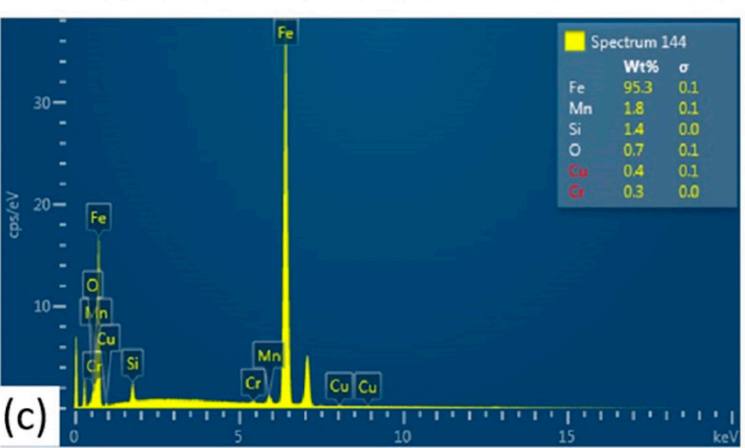

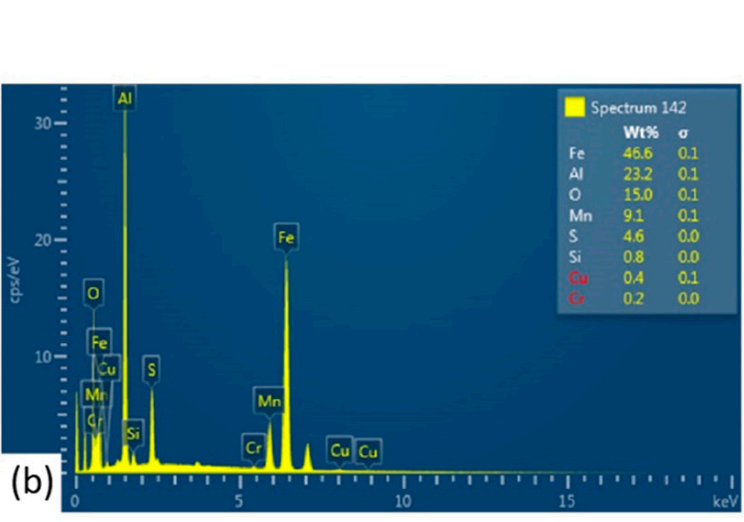

(b)

Figure 12. Mn-Si-HT steel after 20 min immersion (demineralized water), (a) corrosion pit with marked locations for EDS analysis; (b) EDS spectrum-point 1; (c) EDS spectrum-point 2.

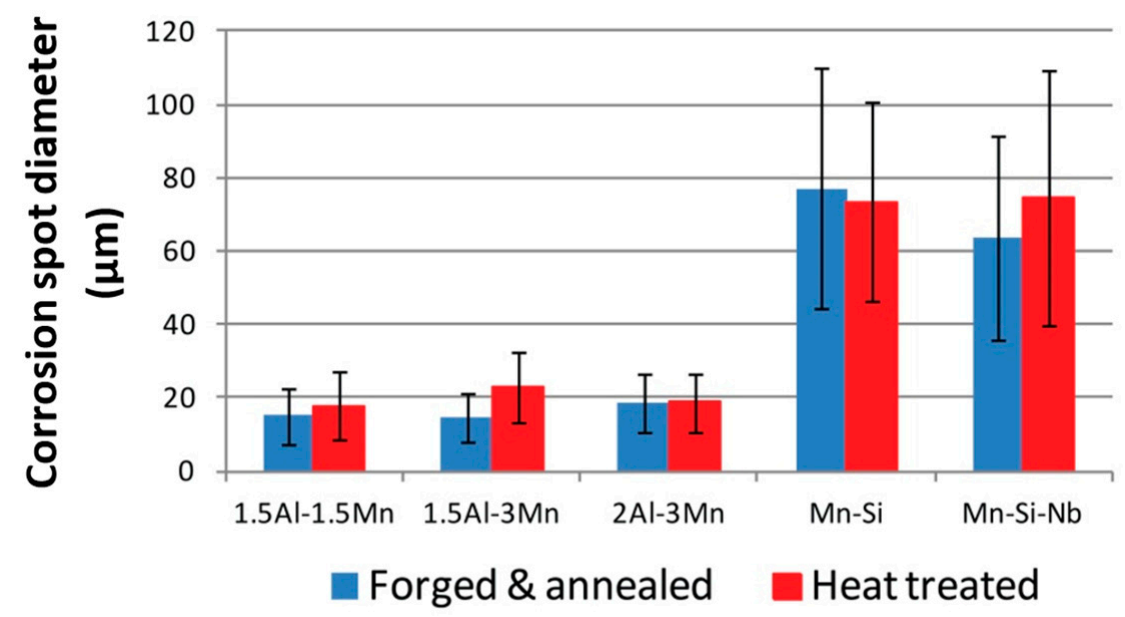

Figure 13. Corrosion spot diameters after $20 \mathrm{~min}$ immersion in demineralized water.

The ability of Al-Mn steels to form sufficiently compact passive $\mathrm{Cr}_{2} \mathrm{O}_{3}$ film on the surface is arguably very low, since their chromium content is only 0.17 and $0.19 \mathrm{wt} . \%$ [39]. Nevertheless, literature reports also different mechanisms of small contents of chromium (under $1 \mathrm{wt} . \%$ ) improving corrosion resistance of steel. Kim et al. [40] suggest that chromium hinders the formation of less stable corrosion products of iron (i.e., magnetite) in neutral solutions while it also promotes nucleation and growth of more stable goethite and contributes to it's grain refinement. For the present study, it can be stated that the steels with increased chromium content possess higher corrosion resistance. However with the methods employed here, it is not possible to distinguish between the effect of chromium 
and the effect of aluminium and to exactly determine the contribution of chromium to the overall corrosion properties of Al-Mn steels.

\subsection{Mechanical Properties}

The overall mechanical tests results (Table 7) show that the heat treatment caused an increase of ultimate strength in all the materials with the exception of $1.5 \mathrm{Al}-1.5 \mathrm{Mn}$, where a slight decrease was observed. For Mn-Si steel, a large relative strength increase $(27 \%)$ was observed after the heat treatment, whereas the highest absolute strength is attributed to $1.5 \mathrm{Al}-3 \mathrm{Mn}-\mathrm{HT}$ steel. The steels with $1.5 \mathrm{wt} . \%$ manganese content exhibit high ductility, ranging from $29 \%$ to $36 \%$ after the heat treatment. Samples with $3 \%$ manganese content reach only $25 \%$ and $23 \%$, which was significantly decreased with the heat treatment. Increased alloying of $6 \mathrm{Al}-4 \mathrm{Mn}$ was apparently detrimental to the mechanical properties, especially total elongation, which reached only $2 \%$ regardless of the heat treatment. In most cases, the impact toughness follows the trends of total elongation, i.e., samples alloyed with $1.5 \%$ wt. aluminium exhibit the highest values. An exceptional increase of the average impact toughness of $90 \%$ and $220 \%$ was observed for $1.5 \mathrm{Al}-1.5 \mathrm{Mn}$ and $\mathrm{Mn}$-Si respectively. In comparison to all of the other samples $6 \mathrm{Al}-4 \mathrm{Mn}$ exhibits extremely brittle behaviour, reaching impact toughness of only $1.1 \mathrm{~J} / \mathrm{cm}^{2}$.

Table 7. Tensile strength, elongation and impact toughness-average results of three test repeats with standard deviation, F\&A—forged and annealed, HT-heat treated.

\begin{tabular}{|c|c|c|c|c|c|}
\hline Group & Material & Condition & $\mathrm{Rm}(\mathrm{MPa})$ & A (\%) & $K_{\mathrm{CV}}\left(\mathrm{J} \cdot \mathrm{cm}^{-2}\right)$ \\
\hline \multirow{6}{*}{$\mathrm{Al}-\mathrm{Mn}$} & \multirow{2}{*}{$1.5 \mathrm{Al}-1.5 \mathrm{Mn}$} & F\&A & $819 \pm 3$ & 30 & $37.4 \pm 0.5$ \\
\hline & & $\mathrm{HT}$ & $802 \pm 3$ & $36 \pm 1$ & $71 \pm 3$ \\
\hline & \multirow[b]{2}{*}{$1.5 \mathrm{Al}-3 \mathrm{Mn}$} & $\mathrm{F} \& \mathrm{~A}$ & $1086 \pm 2$ & $25 \pm 2$ & $23 \pm 2$ \\
\hline & & HT & $1354 \pm 27$ & $14 \pm 1$ & $6.3 \pm 0.5$ \\
\hline & \multirow{2}{*}{ 2Al-3Mn } & F\&A & $1088 \pm 27$ & $23 \pm 1$ & $13 \pm 1$ \\
\hline & & $\mathrm{HT}$ & $1300 \pm 4$ & $15 \pm 1$ & $8 \pm 1$ \\
\hline \multirow{2}{*}{$6 \mathrm{Al}-4 \mathrm{Mn}$} & \multirow{2}{*}{$6 \mathrm{Al}-4 \mathrm{Mn}$} & $F \& A$ & $608 \pm 15$ & 2 & 1.1 \\
\hline & & HT & $693 \pm 51$ & $2 \pm 1$ & 1.1 \\
\hline \multirow{4}{*}{$\mathrm{Mn}-\mathrm{Si}$} & \multirow{2}{*}{$\mathrm{Mn}-\mathrm{Si}$} & $F \& A$ & $669 \pm 1$ & $34 \pm 1$ & $16 \pm 5$ \\
\hline & & $\mathrm{HT}$ & $852 \pm 2$ & $33 \pm 1$ & $50 \pm 2$ \\
\hline & \multirow[b]{2}{*}{$\mathrm{Mn}-\mathrm{Si}-\mathrm{Nb}$} & $F \& A$ & $765 \pm 3$ & $24 \pm 3$ & $21 \pm 5$ \\
\hline & & $\mathrm{HT}$ & $903 \pm 2$ & 29 & $31 \pm 9$ \\
\hline
\end{tabular}

An earlier study on the hot stamping abilities of $\mathrm{Mn}-\mathrm{Si}-\mathrm{Nb}$ steel show very good correspondence of the mechanical properties of the hot stamped material with the values obtained in the present study [41]. With the hot stamping process following the same heating and cooling schedule as in the present experiment, it was possible to reach ultimate strength $899 \mathrm{MPa}$ and total elongation 36\% when evaluated on tensile samples of identical geometry. Moreover, hot stamping experiments with Mn-Si steel, were carried out with the intention to alter the resulting mechanical properties by modifying the process parameters. By performing the deformation step at higher temperatures $\left(800^{\circ} \mathrm{C}\right)$ and subsequent air cooling only slight increase in ultimate strength was reached $(946 \mathrm{MPa})$ while the total elongation decreased significantly (10.8\%) [42]. Therefore, the Mn-Si steel group doesn't appear to be the competitor to commercially used hot stamping martensitic boron steels in terms of ultimate strength [43]. In this regard, Al-Mn group particularly $1.5 \mathrm{Al}-3 \mathrm{Mn}$ might be considered more promising choice for its exceptional strength.

\section{Conclusions}

The properties of six different advanced high strength steels with varying aluminium and manganese contents were evaluated using multiple methods of corrosion testing and mechanical testing. The following findings can be stated: 
The numerical results from potentiodynamic testing did not show any considerable differences in the corrosion resistances of the experimental steels, which however, exhibit better corrosion properties, especially corrosion rate, than the earlier high alloyed manganese-aluminium steel grades. Arguably, the improved corrosion resistance of the steels studied here can also be attributed to relatively low manganese content (1.5 to $4 \mathrm{wt}$.\%), which decreased the significance of soluble corrosion products of manganese.

Further investigation with a combination of corrosion test microscopic analysis, EDS analysis and visual evaluation revealed an increased passivation tendency of $6 \mathrm{Al}-4 \mathrm{Mn}$ steel in the early stage of the corrosion process.

Although the increased aluminium content in $6 \mathrm{Al}-4 \mathrm{Mn}$ reduced the early stage corrosion significantly, it also contributed to the formation of an unfavourable microstructure and thus the mechanical properties, particularly elongation, were decreased dramatically.

The comparison of $\mathrm{Mn}-\mathrm{Si}$ and Al-Mn steels revealed that the partial replacement of silicon with aluminium resulted in approximately $60 \%$ improvement of corrosion resistance in terms of weight losses after the exposure test. This finding was confirmed on the microscale with corrosion pit measurement.

Although the non-metallic inclusions are responsible for initiating the pitting corrosion, the key factor determining the overall corrosion resistance of the experimental steels is the aluminium content. Also, the coarse M/A islands present in the Al-Mn steels evidently contribute to pitting corrosion initiation and development.

Neither the two-step heat treatment process nor the small variations in manganese and niobium content were found to have any quantifiable impact on the corrosion resistance of the experimental steels.

High strength steels with increased aluminium content represent promising materials in terms of increased corrosion resistance and reduced weight. Therefore, designing a heat treatment procedure to improve the mechanical properties of $6 \mathrm{Al}-4 \mathrm{Mn}$ steel, which would facilitate its implementation, appears to be a promising direction for subsequent research. From the corrosion point of view, further testing of real part geometries with real surface finishing and treatment comes into consideration, particularly for 6Al-4Mn to prove its improved corrosion resistance in operating conditions.

Author Contributions: Conceptualization, J.H. and L.K.; methodology, J.H. and K.B.; validation, J.H. and L.K.; formal analysis, J.H. and L.K.; investigation, J.H. and K.B.; resources, J.H. and L.K.; data curation, J.H.; writing — original draft preparation, J.H. and L.K.; writing—review and editing, J.H. and L.K.; visualization, J.H. and K.B.; supervision, L.K.; project administration, L.K.; funding acquisition, L.K. All authors have read and agreed to the published version of the manuscript.

Funding: The present contribution has been prepared with the support of the student grant competition of University of West Bohemia in Pilsen, SGS 2019-019.

Data Availability Statement: Data and results reported in this work are available on request from the corresponding author.

Acknowledgments: The authors are grateful to the Department of Materials and Engineering Metallurgy of University of West Bohemia for providing the corrosion testing facilities.

Conflicts of Interest: The authors declare no conflict of interest. The funders had no role in the design of the study; in the collection, analyses, or interpretation of data; in the writing of the manuscript, or in the decision to publish the results.

\section{References}

1. Keeler, S.; Kimchi, M.; Mooney, P.J. Advanced High-Strength Steels Application Guidelines. World Auto Steel. 2017, 6. Available online: http:/ / www.worldautosteel.org/download_files/AHSS\%20Guidelines\%20V6/00_AHSSGuidelines_V6_20170430.pdf (accessed on 23 November 2020).

2. Billur, E.; Taylan, A. Three generations of advanceed high strength steel for automotive applications, Part 1. Stamp. J. 2013, 16-17. Available online: https:/ / ercnsm.osu.edu/sites/ercnsm.osu.edu/files/uploads/S_FormingAHSS/664-1.pdf (accessed on 23 November 2020). 
3. Kučerová, L.; Jirková, H.; Volkmannová, J.; Vrtáček, J. Effect of Aluminum nad Manganese Contents on the Microstructure Development of Forged and Annealed TRIP Steel. Manuf. Technol. 2018, 12, 605-610.

4. Schmitt, J.-H.; Iung, T. New developments of advanced high-strength steels for automotive applications. Comptes Rendus Phys. 2018, 19, 641-656. [CrossRef]

5. Billur, E.; Taylan, A. Three generations of advanced high strength steels, part 3. Stamp. J. 2014, 12-13. Available online: https://ercnsm.osu.edu/sites/ercnsm.osu.edu/files/uploads/S_FormingAHSS/664-3.pdf (accessed on 24 November 2020).

6. Zhao, P. The potential significance of microalloying with niobium in governing very high cycle fatigue behavior of bainite/martensite multiphase steels. Mater. Sci. Eng. A 2016, 650, 438-444. [CrossRef]

7. Yan, H.; Bi, H.; Li, X.; Xu, Z. Precipitation and mechanical properties of $\mathrm{Nb}$-modified ferritic stainless steel during isothermal aging. Mater. Charact. 2009, 60, 204-209. [CrossRef]

8. Kucerova, L.; Jirkova, H.; Mašek, B. Continuous Cooling of CMnSi TRIP Steel. Mater. Today Proc. 2015, 2, S677-S680. [CrossRef]

9. Zambrano, O.A. A general perspective of Fe-Mn-Al-C steels. J. Mater. Sci. 2018, 53, 14003-14062. [CrossRef]

10. Zhu, X.M.; Zhang, Y.S. Investigation of the Electrochemical Corrosion Behavior and Passive Film for Fe-Mn, Fe-Mn-Al, and Fe-Mn-Al-Cr Alloys in Aqueous Solutions. Corrosion 1998, 54, 3-12. [CrossRef]

11. Kannan, M.B.; Raman, R.K.S.; Khodam, S. Comparative studies on the corrosion properties of a Fe-Mn-Al-Si steel and an interstitial-free steel. Corros. Sci. 2008, 50, 2879-2884. [CrossRef]

12. Zhang, Y.; Zhu, X. Electrochemical polarization and passive film analysis of austenitic Fe-Mn-Al steels in aqueous solutions. Corros. Sci. 1999, 41, 1817-1833. [CrossRef]

13. Wang, Y.; Cheng, G.; Li, Y. Observation of the pitting corrosion and uniform corrosion for X80 steel in $3.5 \mathrm{wt} . \% \mathrm{NaCl}$ solutions using in-situ and 3-D measuring microscope. Corros. Sci. 2016, 111, 508-517. [CrossRef]

14. Wei, J.; Dong, J.H. Influence of Inclusions on Early Corrosion Development of Ultra-Low Carbon Bainitic Steel in NaCl Solution. Corrosion 2015, 71, 1467-1480. [CrossRef]

15. Nam, N.D.; Kim, J.G. Effect of niobium on the corrosion behaviour of low alloy steel in sulfuric acid solution. Corros. Sci. 2010, 52, 3377-3384. [CrossRef]

16. El-Taib Heakal, F.; Shetata, O.S.; Tantawy, N.S. Effects of NB and Cr on the Corrosion Characterization of Al-containing Trasformation-Induced Plasticity Steels in Neutral Cloride Solutions. Corrosion 2011, 9, 67. [CrossRef]

17. Qiao, Q.; Lu, L.; Fan, E.; Zhao, J.; Liu, Y.; Peng, G.; Huang, Y.; Li, X. Effects of Nb on stress corrosion cracking of high-strength low-alloy steel in simulated seawater. Int. J. Hydrog. Energy 2019, 44, 27962-27973. [CrossRef]

18. Zhang, X.; Wei, W.; Cheng, L.; Liu, J.; Wu, K.; Liu, M. Effects of niobium and rare earth elements on microstructure and initial marine corrosion behavior of low-alloy steels. Appl. Surf. Sci. 2019, 475, 83-93. [CrossRef]

19. Kadowaki, M.; Muto, I.; Katayama, H.; Masuda, H.; Sugawara, Y.; Hara, N. Effectiveness of an intercritical heat-treatment on localized corrosion resistance at the microstructural boundaries of medium-carbon steels. Corros. Sci. 2019, 154, 159-177. [CrossRef]

20. Kučerová, L.; Bystrianský, M.; Jeníček, Š. The Effect of Annealing Temperature on Microstructure and Mechanical Properties of Lightweight Steel with Increased Aluminium Content. Manuf. Technol. 2017, 17, 881-887. [CrossRef]

21. Zhao, J.; Jiang, Z. Thermomechanical processing of advanced high strength steels. Prog. Mater. Sci. 2018, 94, 174-242. [CrossRef]

22. Fu, B.; Yang, W.; Li, L.; Sun, Z. Effect of bainitic transformation temperature on the mechanical behavior of cold-rolled TRIP steels studied with in-situ high-energy X-ray diffraction. Mater. Sci. Eng. A 2014, 603, 134-140. [CrossRef]

23. De Cooman, B. Structure-properties relationship in TRIP steels containing carbide-free bainite. Curr. Opin. Solid State Mater. Sci. 2004, 8, 285-303. [CrossRef]

24. Jacques, P. Transformation-induced plasticity for high strength formable steels. Curr. Opin. Solid State Mater. Sci. 2004, 8, 259-265. [CrossRef]

25. Muránsky, O.; Šittner, P.; Zrník, J.; Oliver, E. In situ neutron diffraction investigation of the collaborative deformationtransformation mechanism in TRIP-assisted steels at room and elevated temperatures. Acta Mater. 2008, 56, 3367-3379. [CrossRef]

26. Grajcar, A.; Skrzypczyk, P.; Wozniak, D. Thermomechanically rolled medium-Mn steel containing retained austenite. Arch. Metall. Mater. 2014, 59, 1691-1697. [CrossRef]

27. Gau, Y.J.; Wu, J.K. Galvanic corrosion behaviour of Fe-Mn-Al alloys in sea water. J. Mater. Sci. Lett. 1992, 11, 119-121. [CrossRef]

28. Shih, S.T.; Peng, T.P. Corrosion Behaviour of Two-Phase Fe-Mn-Al alloys in 3,5\% NaCl Solution. Corrosion 1993, $49,130-134$. [CrossRef]

29. Lee, J.W.; Tsai, S.Y. Corrosion Resistance and Microstructural Evaluation of the Chromized Coating Process in a Dual Phase Fe-Mn-Al-Cr Alloy. Surf. Coat. Technol. 2002, 153, 59-66. [CrossRef]

30. Chen, Y.-C.; Lin, C.-L.; Chao, C.-G.; Liu, T.-F. Excellent enhancement of corrosion properties of Fe-9Al-30Mn-1.8C alloy in 3.5\% $\mathrm{NaCl}$ and $10 \% \mathrm{HCl}$ aqueous solutions using gas nitriding treatment. J. Alloys Compd. 2015, 633, 137-144. [CrossRef]

31. Yeganeh, M.; Alavi-Zaree, S.R. A Comparison Between Corrosion Behaviors of Fine-Grained and Coarse-Grained Structures of High-Mn Steel in NaCl Solution. J. Mater. Eng. Perform. 2017, 26, 2484-2490. [CrossRef]

32. Jablonska, M.; Michalik, R. Studies on the Corrosion Porperties of High-Mn austenitic steels. Solid State Phenom. 2014, 227, 75-78. [CrossRef]

33. Kannan, M.B.; Raman, R.K.S.; Khoddam, S.; Liyanaarachchi, S. Corossion Behaviour of Twinning-Induced Plasticity (TWIP) steel. Mater. Corro. 2013, 63, 231-235. [CrossRef] 
34. Guo, P.; La Plante, E.C.; Wang, B.; Chen, X.; Balonis, M.; Bauchy, M.; Sant, G. Direct observation of pitting corrosion evolutions on carbon steel surfaces at the nano-to-micro- scales. Sci. Rep. 2018, 8, 7990. [CrossRef] [PubMed]

35. Grajcar, A.; Grzegorczyk, B.; Kozłowska, A. Corrosion Resistance and Pitting Behaviour of Low-Carbon High-Mn Steels in Chloride Solution. Arch. Met. Mater. 2016, 61, 825-832. [CrossRef]

36. Park, I.-J.; Lee, S.-M.; Kang, M.; Lee, S.; Lee, Y.-K. Pitting corrosion behavior in advanced high strength steels. J. Alloys Compd. 2015, 619, 205-210. [CrossRef]

37. BBaker, M.; Castle, J. The initiation of pitting corrosion at MnS inclusions. Corros. Sci. 1993, 34, 667-682. [CrossRef]

38. Shi, W.; Yang, S.; Dong, A.; Li, J. Understanding the Corrosion Mechanism of Spring Steel Induced by MnS Inclusions with Different Sizes. JOM J. Miner. Met. Mater. Soc. 2018, 70, 2513-2522. [CrossRef]

39. Yanjun, G.; Jinchneg, H.; Liazhu, J.; Tianwei, L.; Yanping, W. Effect of annealing temperature on the mechanical and corrosion behaviour of newly developed novel lean duplex steel. Materials 2014, 7, 6604-6619.

40. Kim, B.; Kim, S.; Kim, H. Effects of Alloying Elements (Cr, Mn) on Corrosion Properties of the High-Strength Steel in $3.5 \% \mathrm{NaCl}$ Solution. Adv. Mater. Sci. Eng. 2018, 2018, 7638274. [CrossRef]

41. Jirková, H.; Vrtáček, J.; Peković, M.; Janda, T.; Kučerová, L. Influence of Chromium and Niobium on the Press-Hardening Process of Multiphase Low-Alloy TRIP Steels. Mater. Sci. Forum 2021, 1016, 636-641. [CrossRef]

42. Jirková, H.; Opatová, K.; Jeníček, Š.; Kučerová, L.; Meza-García, E. The use of advanced high-strength steels in the press-hardening technology. In Proceedings of the 7th International Conference on Hot Sheet Metal Forming of High-Performance Steel CHS2-2019, Lulea, Sweden, 2-5 June 2019; Verlag Wissenschaftliche Scripten: Auerbach, Germany, 2019; pp. 465-473, ISBN 978-3-95735-104-3.

43. Opatová, K.; Jirková, H.; Meza-García, E.; Jeníček, Š.; Vrtáček, J. Mechanical behavior of new press hardening steels at elevated temperatures and technological modeling of their processing. In Proceedings of the 7th International Conference on Hot Sheet Metal Forming of High-Performance Steel CHS2-2019, Lulea, Sweden, 2-5 June 2019; Verlag Wissenschaftliche Scripten: Auerbach, Germany, 2019; pp. 719-726, ISBN 978-3-95735-104-3. 